\title{
Bridging the Gaps
}

\section{Computation to Construction in India}

\author{
Urvi Sheth ${ }^{l}$ \\ ${ }^{I}$ CEPT University \\ I'urvi.sheth@cept.ac.in
}

In the era of The Second Digital Turn, designers and engineers have easy and equal access to computational tools across the globe. With the highest development of technology at a global level, design development to construction process is locally contextualised in different parts of the world based on the available technology and resources. The paper presents a craft-based approach to computation and its contribution to support artisans' development in India. It is demonstrated through ongoing research on customising bricks and utilization of computationally generated asymmetrical Catalan vault. The challenge of constructing the computationally generated form by architecture students is completed by the craftsmen and students of crafts school. The research elucidates gaps at various levels. Craft based solutions bridging these gaps establish a methodology which makes complex geometry constructible in present-day India when access to digital fabrication methods are still evolving and expensive.

Keywords: Digital Crafts India, Customising Bricks, Asymmetrical Catalan Vault, RhinoVAULT

\section{INTRODUCTION}

In the era of The Second Digital Turn, designers and engineers have easy and equal access to computational tools across the globe. Big data sharing and advancements in digital fabrication with a six-axis robotic arm have revolutionised design thinking and making. Robots are being trained to sense information, feedback the process and take independent decisions like the craftsmen of the pre-industrial era.

The hands of Craftsmen have cumulative wisdom of materials, tools and techniques. A craftsmen's hands are directly connected to his/her mind. When craftspeople are introduced to new ideas (in this case complex geometry), tools and techniques (Catalan
Vault), the construction process is as precise as machines. In addition to that, a craftsmen's knowledge and sensitivity to material and making bring an inherent quality without any pre-programmed instructions given to them.

\section{BACKGROUND}

Presented paper is part of ongoing research on customizing brick. The research looks into bricks with two simultaneous yet separate approaches.

The first approach - parts to the whole, is focused on the development of customizing building block (brick). Individual masonry blocks are customized to 
enhance the quality of existing brick. The aim is to make construction without mortar and/or add one of the qualities such as acoustics, thermal insulation, light and shadow on the facade, integration of plantation, etc. Customisation of the block can also be based on self-assembling complex geometries.

Whereas the second approach - whole to parts, is based on a funicular structure. Here, the form is computationally generated and the parts are considered as standard blocks available in the market. The focus is to design and build an asymmetrical vault at an affordable cost in India. The project conferred here is built based on the second approach.

The project conferred here is built based on the second approach.

\section{CONCEPT DESIGN \\ Form finding}

The project was conceptualized by students in a 3week (Winter School 2016) course, Digital Crafts: Customised Bricks 1.1, conducted at Faculty of Architecture, CEPT University, Ahmedabad, India. Students were free to choose a specific site and program on Sabarmati Riverfront edge. A bounding box of the volume of 30 cubic meters $(3 \times 3 \times 3 \mathrm{~m})$ with the possibility to stretch the box keeping the same volume was given to start. This changed to 270 cubic meters $(10 \times 6 \times 4.5 \mathrm{~m})$ while developing the design.

RhinoVAULT which is the Plug-In to Rhinoceros ${ }^{\circledR}$ emerged from research on structural form finding using the Thrust Network Analysis (TNA) approach to intuitively create and explore compression-only structures was introduced as a generative tool. Number and type of supports were site-specific. Five different designs were generated by students working in a group of two. Out of these, children's play area was chosen to develop further [Fig. 1].

\section{Design development}

The plan footprint of $9.5 \times 6.0 \mathrm{~m}$ with 5 boundary supports, two central supports and two cut-outs were fixed. Two central supports to include the details inspired by the teardrop columns (Frei Otto). The allow- able maximum height was limited to $4.5 \mathrm{~m}$. Height in some portion was further reduced to $1.8 \mathrm{~m}$ so that children can climb on the roof and slide down from one of the central support. The form was iterated till all the headroom clearances were achieved with respect to the maximum allowable height and overall aesthetics of the geometry was resolved [Fig. 2].
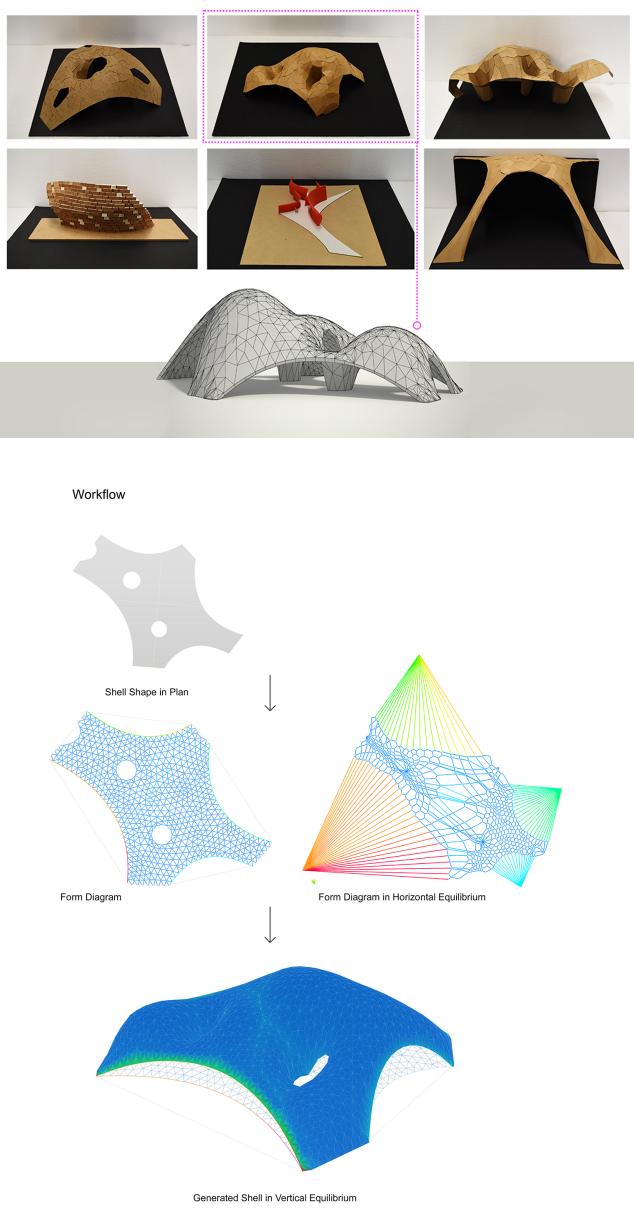

Figure 1

Design options generated in RhinoVAULT. Paper models made using Ivy for Grasshopper

Figure 2 Form finding in RhinoVAULT 
Figure 3

Diagram of construction sequence

Figure 4

Students making

Prototype

(Scale1:5).
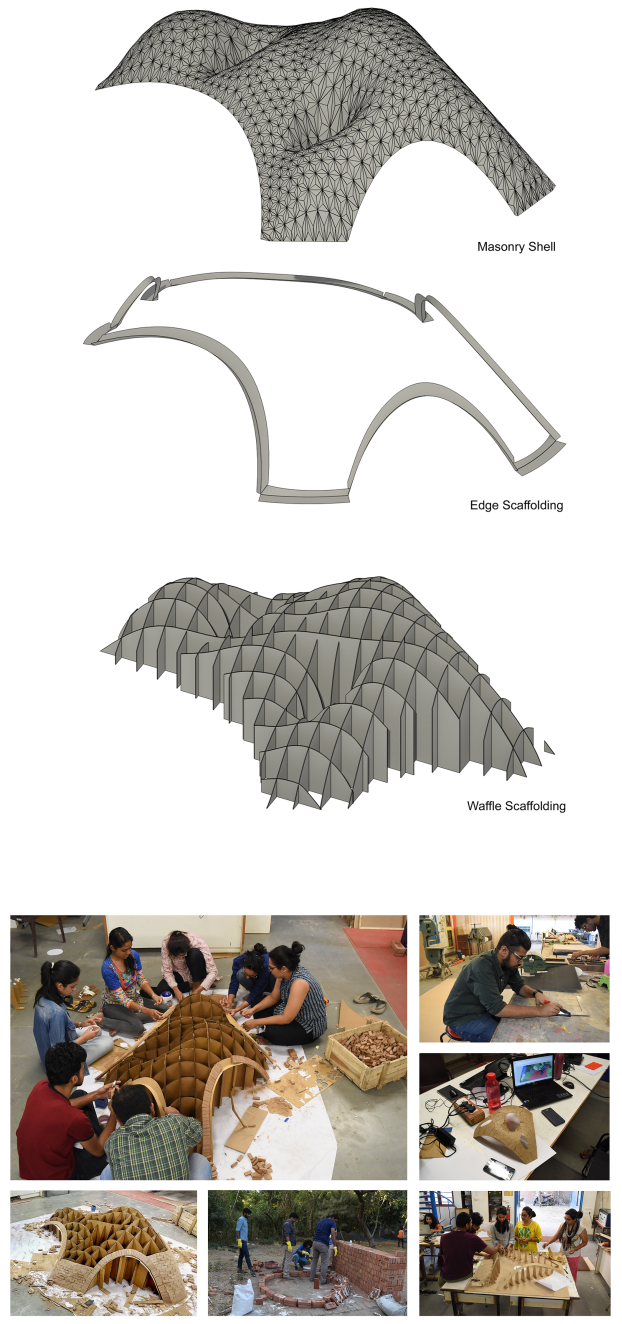

\section{Prototyping (Scale 1:5)}

A stepwise sequence of construction was referred from laaC pavilion (BRG). Step 1, Make a visual guide using cardboard. Step 2, Construct boundary curves using scaffolding. Step 3, Build a masonry shell using MDF bricks between the boundary curves using a visual guide only (without scaffolding). Step 4, Begin construction from the ground to top from all five outer support points. Step 5, Begin with central support once the masonry work from outer support has reached the maximum limit of cantilever without scaffolding. Step 6, Complete the masonry shell on the top [Figure 3].

Students were obliged to build a scaled prototype (scale 1:5) following the set sequence of construction to understand shell behaviour during construction [Figure 4]. Simultaneous attempt to build a dome using standard brick ( $230 \times 115 \times 75 \mathrm{~mm}$ ) and gypsum plaster. Cardboard visual guide was removed and the prototype was presented in the exhibition. This marked the end of Winter School.

\section{LEGAL DIRECTION: ACADEMIA TO PRAC- TICE}

The outcome of Winter School was presented to Ahmedabad Municipal Corporation (AMC). The authorities appreciated and encouraged the research by offering land to build this permanent structure in a park called Shahibag Riverfront Park, located on the eastern bank of Sabarmati river. However, the city engineer demanded us to submit the following as regular formalities for building permission:

- Structure stability certification along with the report describing load calculations and test results by an authorised engineer. \{Notes: Dead load, Live load, wind load and seismic load\}

- Fulfil safety norms for such structure in the public domain.

- Detail 2D working drawings including the cross-section detail showing multiple layers of construction and material specification.

The submission requirement is based on conventional construction and socio-cultural context. 


\section{CHALLENGES}

At this moment in research, there were three biggest challenges: One, detail structure design and certification by an authorised engineer. Two, find craftsmen to build Catalan Vault without scaffolding. Third, limited fund.

\section{Detail Structure Design and Certification by an Authorised Engineer}

Funicular structure is a very well taught theoretical concept among engineering schools in the country, yet, equally uncommon and risky to certify in practice. Auroville Earth Institute has excelled detailing structure design and construction of symmetrical catenary vault in compressed earth blocks (Ref.). The only simultaneous ongoing project of its time in the country by $\mathrm{SP}+\mathrm{a}$ used RhinoVAULT to generate asymmetrical form was also facing exactly similar challenges (Ref).

For detail analysis and verification, the mesh of the generated geometry was transferred to STAAD.Pro. A software most commonly used and trusted by engineers in India. The results were found common and safe, yet, there was a lack of confidence because there was no such structure built and tested till the date. Therefore, the engineer who verified calculations for the project did not certify the design for structural stability.

\section{To find craftsmen to build Catalan Vault without scaffolding and reinforcement}

Masons have excelled constructing domes by corbelling bricks. The technique is mastered over generations since its introduction by Mughals in India. Very few masons can build shallow domes using Catalan Vault techniques. This requires to be constructed within a continuous boundary condition - beam. Rise of such domes is not more than 8 inches. These are most commonly used to construct brick slabs.

Finally, Philip Block (BRG) was contacted by the author to guide construction (meeting in person at Fabricate 2017 Conference). The answer was, "construction of Catalan Vault without scaffolding and reinforcement is highly dependent on skilled masons.
If one doesn't find, one has to train them".

\section{Limited Fund}

Till the date, there are no dedicated funds to conduct research in architecture, specifically in the domain: computational design and digital fabrication. This is a less known field. CEPT University funded the entire project, but the amount was less than USD 10,000. Therefore, neither the appointment of international experts as consultants for structural certification nor importing master masons to show construction technique was not possible.

Resolving these challenges was the longest and low period of 6 months.

\section{CRAFT: BRIDGING THE GAP}

The solution to these challenges was found from Craft Institute, Hunnarshala Foundation located in the western part of the country. The institute was also researching on Catalan Vault construction during that period. Masons of Karigarshala were trained to build a smaller $(1.5 \times 1.5 \mathrm{~m})$, symmetrical vaults. The failure pattern was studied by physical load testing. Joint research between the two institutes was established to work further.

\section{Data Transfer}

Along with the $.3 \mathrm{dm}$ model, a complete set of $2 \mathrm{D}$ drawings [left part of Fig. 5] were given to the team. One of the architectural interns handled 3D model. The curvature of each section was studied for detail structure analysis [right part of Fig. 5].

\section{Material and Construction Detail}

The first decision changed was the choice of material. It was recommended to use thin clay tile (fired) measuring $230 \times 75 \times 12 \mathrm{~mm}$ instead of the standard brick module which is $230 \times 115 \times 75 \mathrm{~mm}$. This was simply to reduce the dead load of the structure.

The assumption was made that a minimum of 3 layers of construction will be required. First layer with clay tile and gypsum mortar to achieve the desired shape. This will be plastered with $25 \mathrm{~mm}$ thick ce- 
Figure 5

(upper left ) Plan view of projected boundary curves on the ground with grid $600 \times 600 \mathrm{~mm}$ (lower left) Contour layout (right)

Sections at grid line A to $I$ and 1 to 15
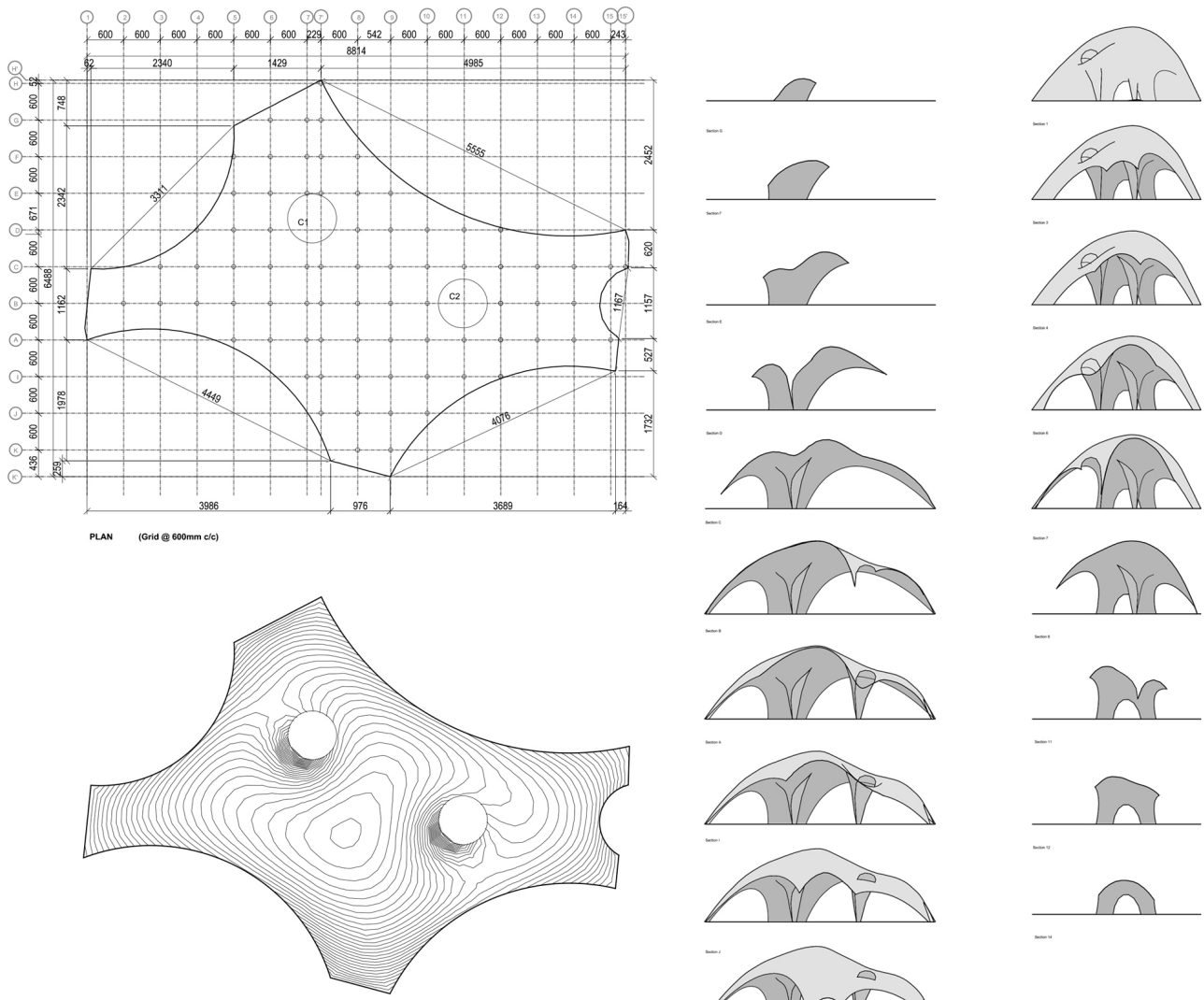

CONTOUR PLAN (Top View)
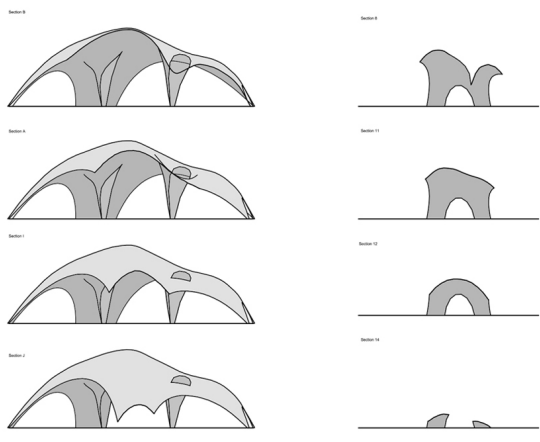

ment mortar on both sides, top and bottom. The second and third layer of tile on the top and the bottom to be constructed with fine cement mortar (ratio 1:2) to achieve the desired strength and protect the first layer from weathering and collapsing. More layers could be added, if required, after load testing.

\section{Prototype (Scale 1:1)}

The decision to build a prototype (scale 1:1) to train the masons as well as for physical load testing was taken. The construction sequence followed by stu- dents to build Prototype (Scale 1:5) was explained to the team of craftsmen and students of the craft school. Referring to the Drone Port Pavilion [Fig. 6], the making of visual guide differed from the earlier one made in cardboard. Advantage of the visual guide made of pipes allows workable space from the bottom.

Training Masons. Due to the asymmetric geometry and sharp curves of the form, it was further required to increase the precision of the visual guide. Therefore, the plan grid at $600 \times 600 \mathrm{~m}$ was revised to 
$300 \times 300 \mathrm{~mm}$. The perpendicular distance from the ground to the required surface was given at the intersection of the grid [Fig. 7].

Arches were built first, followed by surface, starting from all five outer ground points at a time. Tiles were precisely cut and shaped wherever required to achieve accurate double curved surface. Preparation of small portion of gypsum mortar was key to hold tiles in its location in space [Fig. 8].

Construction of teardrop columns required a special set of drawings [Fig. 9] to build the geometry. Figure 10 shows a piece of craft, marking the end of training the masons and construction of the prototype.
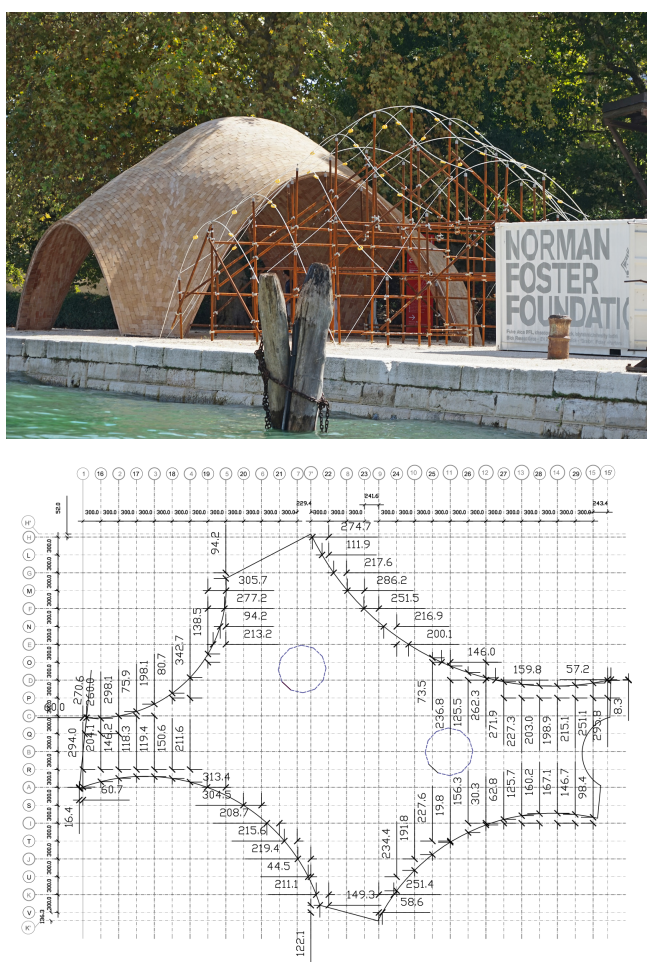

\section{CONCLUSION AND WAY FORWARD}

Construction Industry and Cultural Acceptance.

Though India is known for its Information technology contribution to the world, it takes a decade or sometimes, even more, to percolate technological advancements in architecture and construction industry when compared to the global status. We are now in the first digital turn and India is still a labourintensive construction industry. The cost of digital fabrication is still too high when compared to the cost of manual labour (craftsmanship). Often, the time taken to complete a project is not considered as the biggest resource hence it encourages craftsman-
Figure 6

The Droneport Pavilion, Venice Biennale 2016

Figure 7

Revised plan Grid at $300 \times 300 \mathrm{~mm}$ with vertical distances at intersection 
Figure 8

Craftsmen training while building the first layer of construction

Figure 9

Drawings for two teardrop columns
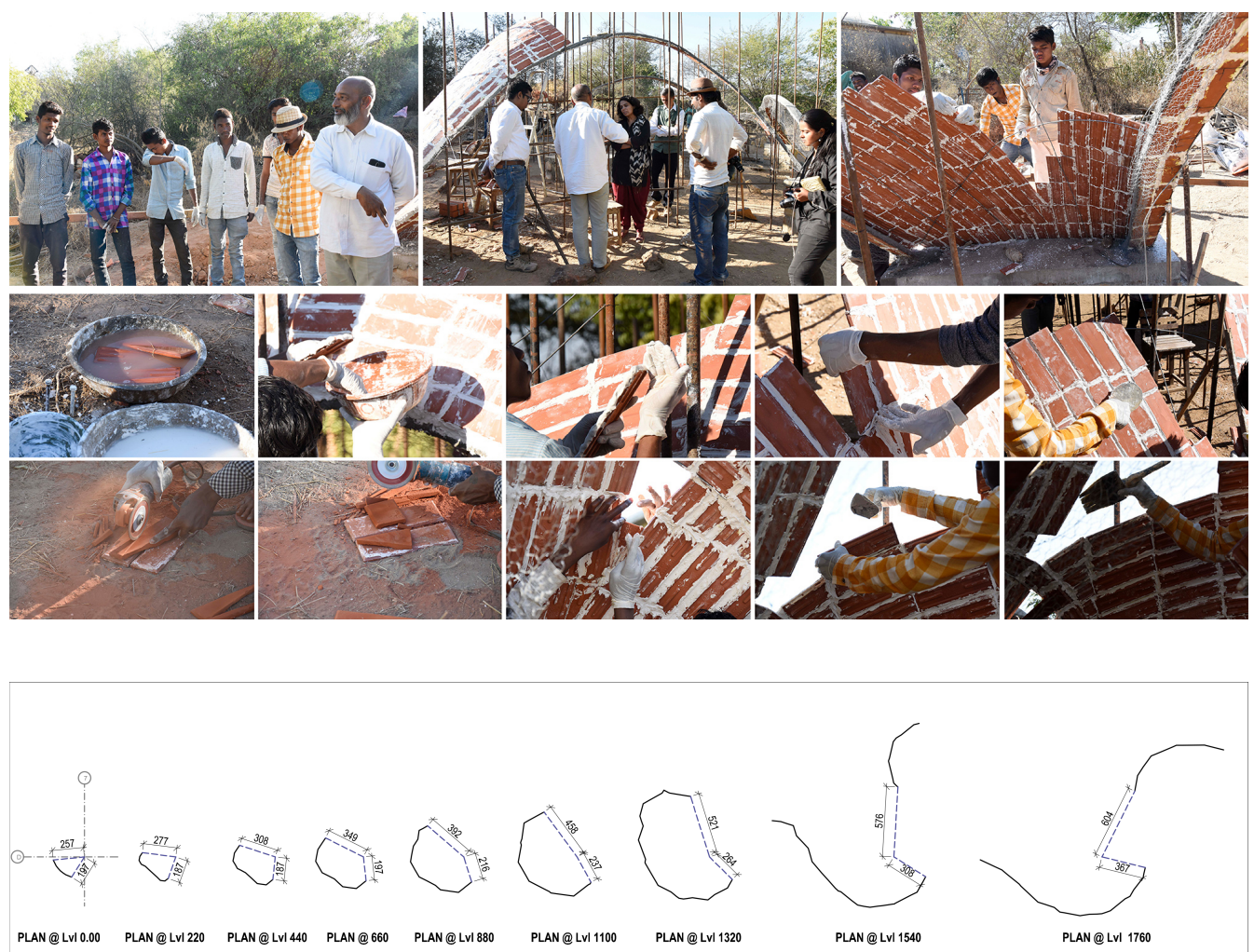

PROFILES FOR COLUMN C1

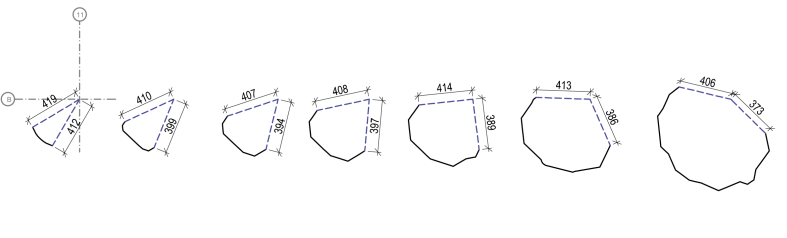

PLAN @ LV1 $0.00 \quad$ PLAN @ LVI $220 \quad$ PLAN @ LVI $440 \quad$ PLAN @ $660 \quad$ PLAN @ LVI 880

PLAN @ Lv1 1100

PLAN @ LVI 1320

PROFLLES FOR COLUMN C2
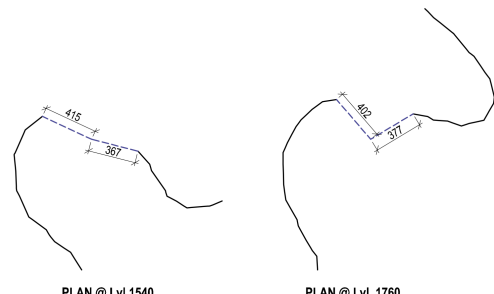

PLAN @ LVl 1760 


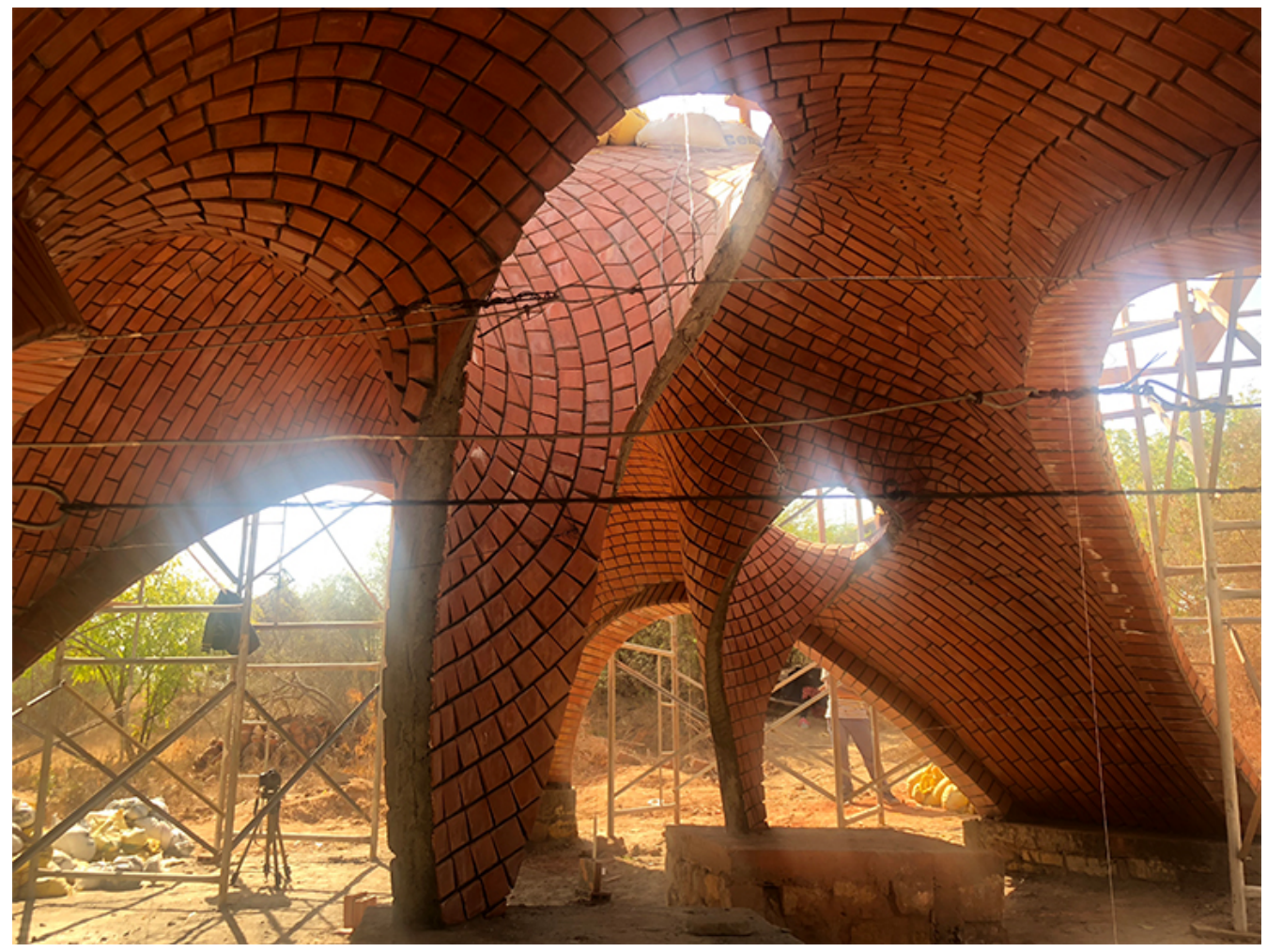

Figure 10

Prototype ready for load test
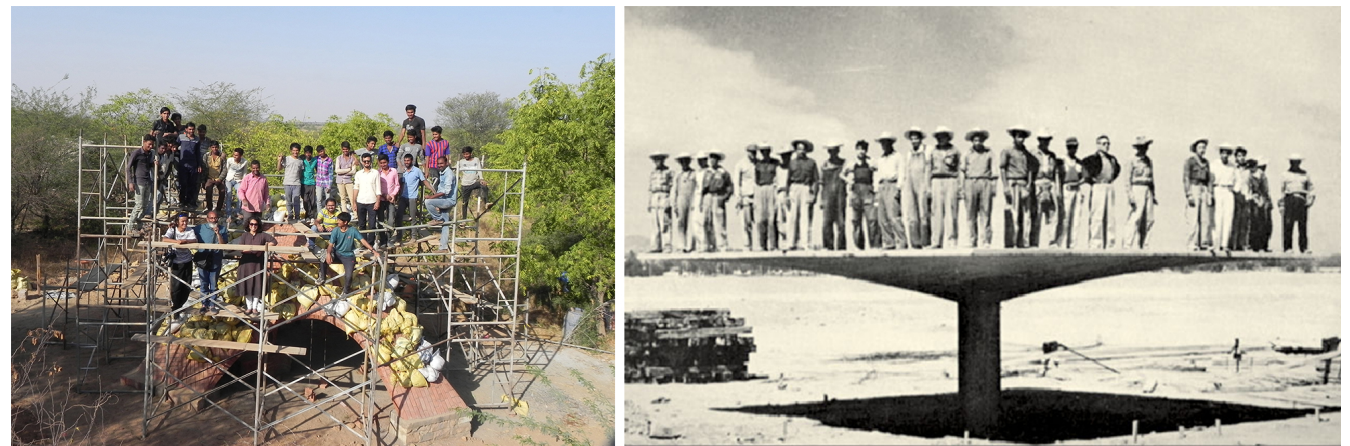

Figure 11

Physical load test similar to the thin concrete shell by Candela. 
Figure 12

Construction on site

Figure 13

Additions on site
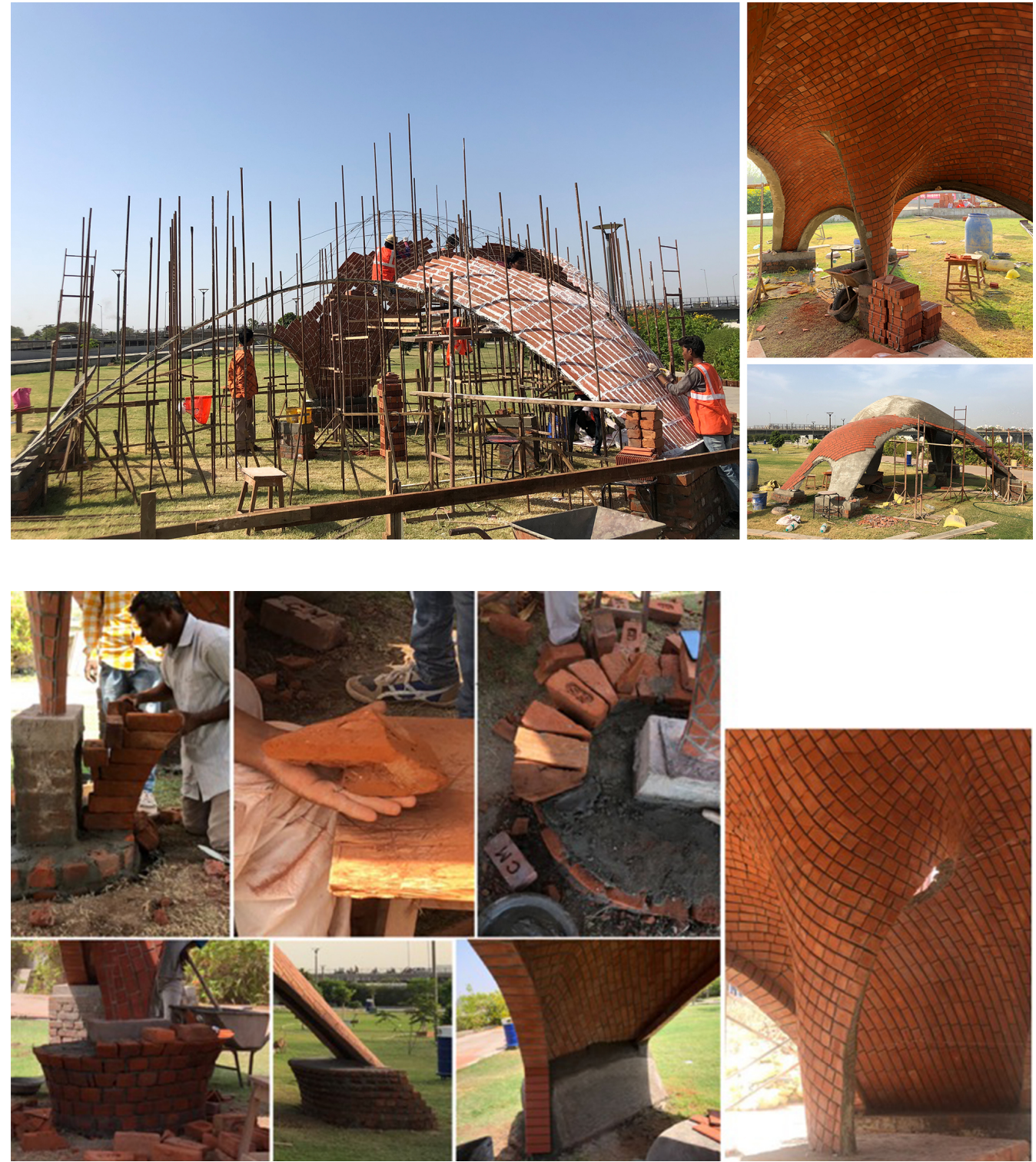
ship and speed of work delivered by the machines become obsolete. At present, it is most efficient to establish a balance between digital fabrication and craftsmanship to build a project with complex geometry.

\section{Architecture, Engineering and Craft Education.}

Awareness of the advancements in technology and shard tools among designers/architects in India is relatively at par with the world. Architecture and design schools conduct a full-time course and/or specialisation in the field. Architectural practices also began to accept the digital turn positively.

There is a clear demand for updating civil and structural engineering education. Analytical methods taught and practised by the engineers are extensive, accurate yet not enough to be able to share mutually between designers and engineers. These methods are limited to symmetrical shapes. To be able to calculate the structural behaviour of asymmetrical free-form without digital tools in today's time will demand alternative methods, similar to the one used by Antoni Gaudi, Frei Otto and Phelix Candela.

Vocational training like Industrial Training Institutes (ITI) in India and Skill development schools like Hunnarshala must include construction craftsmanship like masonry, fabrication, carpentry and other related subjects. Skilled labour and educated craftsmen can change the face of the Construction Industry in India.

\section{ACKNOWLEDGEMENT}

CEPT University: Shehzad Irani, Avishek Das, Arunima Sen, Ekta Samani, Naindeep, Faisal, Parv Modh, Chaitali, Sudarshana Babu, Students of Digital Crafts: Customised Bricks 1.1 (Winter School 2016); Hunnarshala Foundation and students of Karigarshala: Kiran Vaghela, Tejas Kotak, Sunil Dheda, Bharat Chauhan, Pangu Sinh Bamania, Jignesh Gor, Itesh Dhadhar, Students of Karigarshala (Batch of '17-'18).

\section{REFERENCES}

Block, P, Bayl-Smith, M, Schork, T, Bellamy, J and Pigram, D 2014 'Ribbed tile vaulting - Innovation through two design-build workshops', FABRICATE 2014, Zurich, pp. 22-29

Carpo, M 2016, The Second Digital Turn: Design Beyond Intelligence, The MIT Press, Cambridge and London

Davis, L, Rippmann, M, Pawlofsky, T and Block, P 2012 'Innovative Funicular Tile Vaulting: A prototype in Switzerland', The Structural Engineer, pp. 46-56

López López, D, Domènech Rodríguez, $M$, Brazo Ramí-rez, J and Block, P 2014 'Thin-tile vault for the seventh World Urban Forum in Medellin', Proceedings of the IASS-SLTE 2014 Symposium, Brasilia, Brazil

Pallasmaa, J 2009, 'The Thinking Hand: Essential and Embodied Wisdom in Architecture', in Pallasmaa, J (eds) 2009, AD Primers, John Wiley \& Sons Ltd, Italy, p. 50, $51,59,63$

Rippmann, M, Lachauer, L and Block, P 2012, 'RhinoVAULT - Interactive Vault Design', International Journal of Space Structures, 27(4), pp. 219-230

Alnais Anda de X., E 2008, 'Felix Candela 1910-1997 The Mastering of Boundaries', in Gossel, Bremen, P (eds) 2008, Candela, Taschen, Germany, p. 9

[1] https://portfolio.cept.ac.in/archive/digital-crafts-cus tomised-bricks-1-1/

[2] https://www.fosterandpartners.com/news/archive/ 2016/05/norman-foster-s-droneport-prototype-goes-o n-show-at-the-venice-biennale-2016/

[3] https://www.sp-arc.net/?p=39 